WEN-KAI K. HSU, Professor ${ }^{1}$

E-mail:khsu@nkust.edu.tw

SHOW-HUI S. HUANG, Professor ${ }^{2}$

E-mail: hsheree@stu.edu.tw

NGUYEN TAN HUYNH, Ph.D student $t^{1,3}$

(Corresponding author)

E-mail: i108189105@nkust.edu.tw,

huynhtannguyen@dntu.edu.vn

${ }^{1}$ Department of Shipping and Transportation Management National Kaohsiung University of Science and Technology 142, Hai Jhuan Rd, Nanzih District, Kaohsiung County, 81157, Taiwan, ROC

2 Department of Incentives, Conferences, Exhibitions and Trade Marketing, Shu-Te University

59, Hun Shan Rd, Yen Chau District, Kaohsiung County, 82445, Taiwan, ROC

${ }^{3}$ Faculty of Economics and Management,

Dong Nai Technology University,

Bien Hoa, Dong Nai, 76000, Vietnam
Science in Traffic and Transport Original Scientific Paper Submitted: 31 Mar. 2021 Accepted: 9 Sep. 2021

\title{
AN EVALUATION MODEL FOR FOREIGN DIRECT INVESTMENT PERFORMANCE OF FREE TRADE PORT ZONES
}

\begin{abstract}
With the tendency of internationalisation and globalisation, signing regional economic agreements among multiple countries has become a trend. Under such an integration environment, some free economic zones with port transportation functions have become crucial for FDI (foreign direct investment) investors in selecting investment locations. The free trade port zone (FTPZ) is argued to be one of the most well-known. This paper aims to assess the FDI performance of FTPZs. On the basis of the FTPZ's features and relevant literature, assessment criteria (ACS) are initially identified. An evaluation model based on the fuzzy AHP (Analytic Hierarchy Process) approach is then introduced to evaluate the FTPZs' FDI performance from foreign investors' viewpoints. Finally, the FTPZ of the Kaohsiung port in Taiwan was empirically investigated to verify the assessment model. Results point out that for the FTPZ of Kaohsiung port, ACs with higher priorities needing improvement are raw material acquired, local government efficiency, and political stability and social security. Theoretical and practical recommendations for the FTPZ managers are discussed based on the results.
\end{abstract}

\author{
KEYWORDS \\ foreign direct investment, performance, fuzzy AHP, free \\ trade port zone.
}

\section{INTRODUCTION}

According to the tendency of internationalisation and globalisation, signing the FTA (free trade agreement) between two countries or REA (regional economic agreement) among multiple nations has become a trend [1]. Under such an integration environment, many new production models have been developing whereby manufacturers may produce their products in different nations and then sell them across the globe. Nevertheless, to enhance production efficiency, the production model needs an effective transportation system and customs clearance. Thus, some free economic zones with port transportation functions have become crucial for the FDI investors in selecting investment locations. The free trade port zone (FTPZ) is thus considered one of the most popular models.

There are currently several forms of free economic zones similar to FTPZ all over the world, such as the international logistic zone, distribution park, custom free zone, free trade zone, foreign trade zone, free port zone. FTPZ is a combination of the free port zone (FPZ) and the free trade zone (FTZ). In general, an FPZ locates in a port's hinterland where firms may perform tax-free production operations, including the importation of raw 
materials, storage, processing, and the export of final products for sale. We know that the port's hinterland in FPZs is often narrow; thus, investors may not set up their factories, especially large-scale processing plants, in the zone. It is argued that the stationed firms located in FPZs are normally logistical companies whose main duties are to either perform light manufacturing or temporarily import for re-export. An FTZ (free trade zone) is defined as a given zone inland, in which the companies in such a location have economic benefits, such as tax-free activities, as in FPZs. In principle, those firms are located inland; hence, many large-scale deep processing enterprises might be easily established in the FTZs. It is said that the vast majority of the enterprises in FTZs are manufacturers. More specifically, the most common types of FTZ in Taiwan are bonded factories and warehouses, import-export processing zones, as well as scientific and industrial regions.

Based on the features of the FPZs and FTZs features, this paper defines an FTPZ as an economic area that integrates manufacturing activities with land, sea [2], air transportation, storage [3], port and customs operations [4] to achieve efficient distribution of commodities. Practically, an FTPZ is also a special economic zone characterised by a relatively high level of trading-liberalisation and internationalisation. Therefore, investment operations in an FTPZ may be regarded as an FDI [5]. Preceding studies argued that FTPZs have a significantly positive effect on attracting FDIs, which have always been drivers of a country's economy [6]. Presently, there are globally over 600 port zones with functions that are comparatively similar to the FTPZ, such as Shenzhen port (Mainland China), Gwangyang port (South Korea), Jebel Ali Port (Middle East area), Jurong port (Singapore), Pecem port (Brazil), Antwerp port (Belgium), Durban port (South Africa), etc. Those FTPZs succeed in attracting a huge amount of FDI capital for host countries, and also significantly contribute to the host countries' economic growth and developments, such as GDP growth, employment creation, and economic structural change.

Since an FTPZ possesses both the FPZ's logistic function and FTZ's production function, the stationed firms could be logistic firms or producers. Nonetheless, Lu, Liao [3] predicted that a container's value-added could grow from $\$ 1,625$ to $\$ 4,750$ with light manufacturing, particularly to $\$ 18,500$ with deep processing. Thus, from the viewpoint of economic benefits, the main objective for FTPZ managers to promote should be the FDI manufacturers.

Nonetheless, although an FTPZ (or schemes similar to an FTPZ) is relatively well-known worldwide, some FTPZs in some nations fail to attract investment operations. Apparently, to successfully attract long-term FDI capital, the FTPZ operators (port companies) may need to understand the real requirements of the FDI investors and improve their FTPZ investment environment to satisfy their concerns. Still, most prior studies have focused on the impact of environmental factors on the FDI decisions based on the features of investment areas. Deng, Wang [7] argued that not many studies have investigated the FDI decisions on FTPZs so far. Unlike the conventional FDI, any investment operation in an FTPZ, besides manufacturing, also emphasise operations at ports, such as sea or air transportation, terminals, and customs.

This paper aims to assess the FDI performance of FTPZs from the perspectives of foreign manufacturers (i.e., FDI investors). This study defines FDI performance as perceived satisfaction of the FDI investors with the investment environment of FTPZs. The higher satisfaction the FDI investors perceive, the higher performance an FTPZ has. Based on the relevant literature and unique features of FTPZs, assessment criteria (ACs) are first constructed. Because FTPZ investment operations are strongly professional problems, a fuzzy AHP (analytic hierarchy process) approach is then used to weight those ACs. An assessment model for FDI performance of the FTPZs is then proposed. Finally, foreign manufacturers around the FTPZ in the Kaohsiung port in Taiwan are empirically investigated to assess the validity of the proposed model. Taiwan currently has seven FTPZs, including six seaports and one airport. However, the FTPZ of the Kaohsiung port is the largest.

The remainder of this article is structured as follows: Section 2 presents literature reviews while Section 3 describes the research methods. Results and discussions are subsequently detailed in Section 4, whilst conclusions and limitations for future studies are presented in Section 5.

\section{LITERATURE REVIEW}

Prior literature has argued that FTPZs might consist of international logistical areas (ILAs), free trade port areas (FTPA), etc. According to Lu and 
Yang [8], the investment environment of international logistics zones consists of four assessment criteria with 14 sub-criteria. These are the market (GDP growth and population), political issue (political stability, safety and security, administrative efficiency and liberalisation for investment activities), costs (land charges, wages and economic incentives), and infrastructure (communication and transportation network, effectiveness of port operations, delivery of fuels, labour sources). By expanding the findings of $\mathrm{Lu}$ and Yang [8], Lu, Liao [3] investigated the impact of investment incentive campaigns on ILAs. Consequently, 35 investment incentives converge eight factors, including port, cost, resource, agglomeration, policy, location and transport, economic and political stability. The results suggest that the most significant incentive is political stability. Other factors also significantly affect FDI attraction, such as business tax-exemption, governmental administrative efficiency, and the types of costs (i.e., labour wages and energy cost). When evaluating the development of hinterland in Taiwanese FTPZs, Yang [9] identified five critical evaluation criteria with 20 sub-criteria, namely, container terminal operations, costs, infrastructure systems, governmental supports, political issues, and economic growth. Notably, the top five sub-criteria considerably impacting the development of hinterland in Taiwanese FTPZs comprises container terminals efficiency, financial incentives, political stability, population size, and efficiency for customs clearance. Chiu, Lirn [10] deployed twenty-eight evaluation indices to assess the FTPZ policy in the context of Taiwan. Mostly, stationed firms were concerned with indexes, including government administration efficiency, rental charges, customs clearance process, and governmental assistance. Based on the cross-sectional point of view, Chang, Ye [5] examined obstacles for enterprises to invest in the FTPZ of the Kaohsiung port. The paper explored fifteen evaluation criteria preventing FDI investors from investing. These are customs bureaucracies, operation effectiveness, labour issues, and processing. More specifically, customs bureaucracies and operation effectiveness are demonstrated to be the most major difficulties for manufactures to invest and operate. Antecedents of investment attraction in Chinese FTPAs were also investigated by Deng, Wang [7] on the basis of logistical operators' viewpoint. By adopting the Delphi approach, along with the integration of the fuzzy AHP and TOPSIS,
Deng, Wang [7] postulated that the most critical criteria for FTPAs operations consist of potentials for economic growth and investment environment. The result also showed that Yangshan located in the Shanghai port is the best potential FTPA in Mainland China for FDI attraction. Chen, Wan [11] evaluated and compared the development performances of six FTPZs in China, including Tianjin Dongjiang, Yangshan, Ningbo Meishan, Yantai, Xiamen Haicang, and Guangzhou Nansha. Five criteria with 23 sub-criteria were first created. An AHP-GRAY method was then suggested to evaluate the development performance of the six FTPZs. The results demonstrated that the economic foundation and supporting policies have the most significant effects on the development performance of FTPZs. Further, the FTPZs around Yangtze River Delta (Yangshan) and Bohai Economic Rim (Tianjin Dongjiang) have the highest development performance.

Although prior literature succeeds in assessing investment activities in FTPZs, its main limitation is the method deployed. Hsu and Kao [2], and Hsu, Lian [12] argued that the decisions for port-related operations could be considered as the multi-criteria decision-making problem that is quite complicated. To deal with this issue, the existing literature has also intensively employed the port performance evaluation methods, such as the capital-budgeting technique [6], IPA [10], AHP [5, 11], TOPSIS [7], and grey relational analysis [11]. Yet, the primary drawback of these methods is the crisp numbers basis; thus, judgments may be imprecise, vague, and especially uncertain. Therefore, this paper utilises the fuzzy AHP, which adopts fuzzy numbers to incorporate vagueness, imprecision, and uncertainty into performance judgements. Deng, Wang [7] likewise postulated the practical application of the fuzzy AHP approach under an uncertain environment.

\section{RESEARCH METHOD}

\subsection{Research framework}

The research flowchart is schematically shown in Figure 1. The assessment criteria (ACs) are first created. Then, a fuzzy AHP method is deployed to calculate weights for ACs, including both weights of importance and satisfaction from foreign investors' viewpoints. On the basis of those weights, an assessment model is ultimately suggested to evaluate 


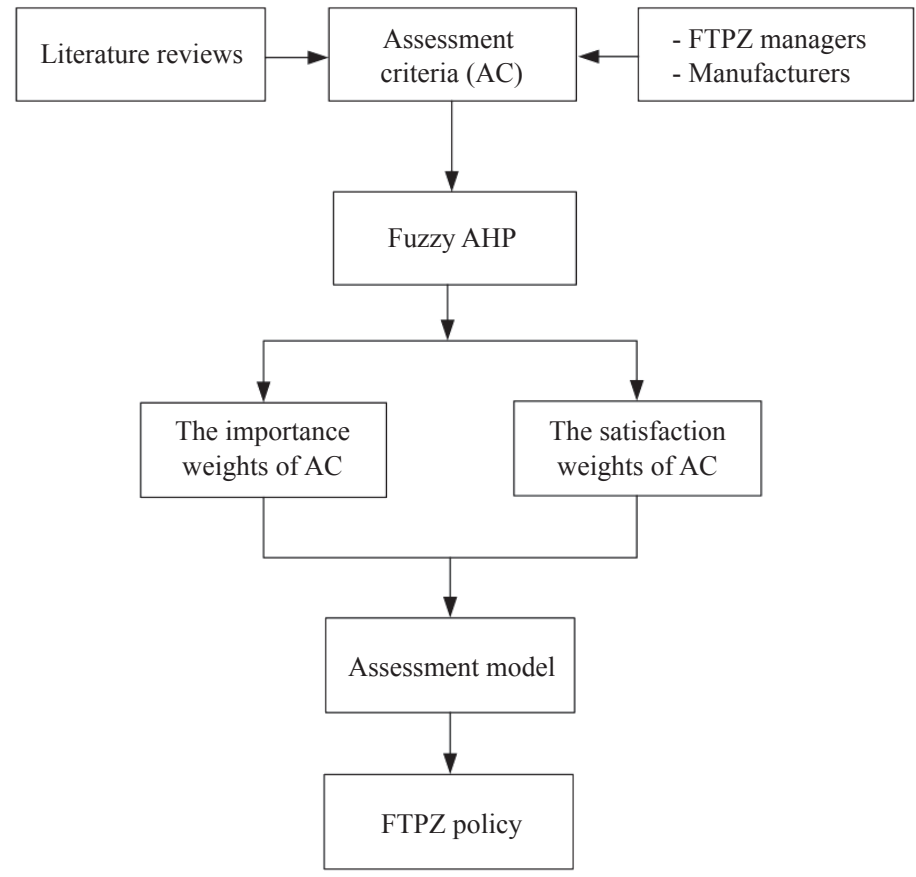

Figure 1 - The research framework

the FDI performance of FTPZs, by which policies for improving the FTPZ's investment environments are suggested for FTPZ authorities.

\subsection{The assessment criteria}

By literature reviews mentioned above and indepth interviews with foreign industrial manufacturers in the Kaohsiung port, four constructs of assessment criteria (ACs) for the FDI performance of FTPZs are created, including government and economy, production, costs, and infrastructure.

Government and economy (GE) is defined as official investment areas, including government political stability, administration efficiency, investment guarantees and market growth rate, etc.

Production (PD) is defined as production environments of investment areas, including the supply of raw material, financings, labour quality, supply chain of upstream and downstream firms, etc.

Costs (CT) is defined as the production costs, including land costs, labour wages, raw material costs and incentives of taxes, etc.

Infrastructure (IS) is defined as production and transport facilities, including inland transportation, port logistics, energy supply and communication systems, etc.

As a result, a two-layer hierarchical structure of ACs is created. The first layer includes four criteria while 18 corresponding sub-criteria are in the second layer.

\subsection{The overview of the fuzzy AHP}

The AHP approach was developed by Saaty in the 1980s [13]. It has also been considered an effective tool for solving MCDM problems. The principal of AHP procedures is to find the relative priorities (or "weight") from a pairwise comparison matrix, which result from experts' subjective judgments. Note, however, that judgments in the AHP process are individual opinions, which is why the AHP result is often not robust. Instead, the fuzzy AHP method is deployed in many practical applications to surmount this challenge.

Saaty [14] suggested a 5-step procedure for the application of the AHP:

1) Identify the problem's goal.

2) Determine criteria and establish the hierarchical structure for them.

3) Construct pairwise comparison matrices (PCM) with the size of $n \times n$ via the individual's subject evaluation using the relative scale measurement. The PCMs will be done according to the way an element dominates the others.

4) Some techniques, such as NGMR (Normalisation of the Geometric Mean of the Rows), NRA (Normalisation of the Row Average), NRSC (Normalisation of the Reciprocal of Columns Sum), and ANC (Average of Normalised Columns) might be used to weight the PCMs. 
5) Based on the result in Step 4, the consistency is tested by adopting the maximum eigenvalue $\left(\lambda_{\max }\right)$ to reckon the consistency index and the consistency ratio. Judgment consistency can be verified if the $\mathrm{CR}$ value is less than $10 \%$. Otherwise, PCMs must judge again until they reach consistency.

In this paper, the application of the fuzzy AHP is detailed in Section 3.6.

\subsection{Questionnaire design}

By employing a fuzzy AHP method to weight ACs, a 9-point expert questionnaire was designed to record the respondents' perceived importance and satisfaction with ACs. According to the ACs in Section 3.2, the expert questionnaire containing four criteria and 18 sub-criteria was created. To verify measurement scales, the questionnaire was first checked by two practical foreign manufacturers and then pre-tested by two other manufacturers to check if statements were easy to understand and whether any essential items were omitted. The four manufacturers were also asked to identify independences among ACs. The ACs with high correlations would be merged. After deleting one $\mathrm{AC}$ and combining two highly correlational ACs into one AC, the final ACs as shown in Table 1, include four criteria (constructs) in the first layer and sixteen sub-criteria (ACs) in the second layer.

\subsection{Research sample}

As this paper conducted the empirical study using the case of FTPZ in the Kaohsiung Port, the research population is defined as the foreign manufacturers (investors) around the Kaohsiung Port. Further, this article used an AHP expert questionnaire as a research tool; subjects in the survey must meet the following criteria: (1) they have experienced in the import or export departments, and (2) they have sufficient experiences and knowledge of FTPZ operations. Based on these criteria, we invited 40 experts to take part in our interview; but only

Table 1 - The assessment criteria of the investment environment in FTPZs

\begin{tabular}{|c|c|c|c|}
\hline $\begin{array}{l}\text { Layer 1: } \\
\text { Constructs }\end{array}$ & Code & Layer 2: ACs & References \\
\hline \multirow{4}{*}{$\begin{array}{l}\text { Government } \\
\& \text { economy } \\
\text { (GE) }\end{array}$} & GE1 & $\begin{array}{l}\text { Political stability and social } \\
\text { security }\end{array}$ & Chen, Wan [11], Chiu, Lirn [10] \\
\hline & GE2 & Local government efficiency & $\begin{array}{l}\text { Chen, Wan [11], Chiu, Lirn [10], Huang, Tseng [4], Lu and } \\
\text { Yang [8] }\end{array}$ \\
\hline & GE3 & Investment guarantees & $\begin{array}{l}\text { Chen, Wan [11], Chiu, Lirn [10], Chang, Ye [5], Hsu and Kao } \\
\text { [2] }\end{array}$ \\
\hline & GE4 & Demand and market size & Chiu, Lirn [10], Huang, Tseng [4], Lu and Yang [8] \\
\hline \multirow{4}{*}{$\begin{array}{l}\text { Production } \\
\quad \text { (PD) }\end{array}$} & PD1 & $\begin{array}{l}\text { The supply chain of upstream } \\
\text { and downstream firms }\end{array}$ & Huang, Tseng [4], Lu and Yang [8] \\
\hline & PD2 & Labour quality and supply & $\begin{array}{l}\text { Chen, Wan [11], Chiu, Lirn [10], Huang, Tseng [4], Lu and } \\
\text { Yang [8] }\end{array}$ \\
\hline & PD3 & Raw material acquired & Chen, Wan [11], Huang, Tseng [4], Lu and Yang [8] \\
\hline & PD4 & Funds acquired & Chiu, Lirn [10], Lu, Liao [3], Lu and Yang [8] \\
\hline \multirow{4}{*}{$\begin{array}{l}\text { Costs } \\
(\mathrm{CT})\end{array}$} & $\mathrm{CT} 1$ & Costs of land acquirement & $\begin{array}{l}\text { Chen, Wan [11], Chiu, Lirn [10], Huang, Tseng [4], Lu and } \\
\text { Yang [8] }\end{array}$ \\
\hline & $\mathrm{CT} 2$ & Labour costs & Chiu, Lirn [10], Lu and Yang [8], Lu and Yang [8] \\
\hline & CT3 & Tax incentives & $\begin{array}{l}\text { Chen, Wan [11], Chiu, Lirn [10], Huang, Tseng [4], Lu and } \\
\text { Yang [8], Hsu, Huang [15] }\end{array}$ \\
\hline & $\mathrm{CT} 4$ & Supplies costs & Interviews \\
\hline \multirow{4}{*}{$\begin{array}{l}\text { Infrastructure } \\
\text { (IS) }\end{array}$} & IS1 & $\begin{array}{l}\text { The efficiency of port opera- } \\
\text { tion (customs) }\end{array}$ & $\begin{array}{l}\text { Chen, Wan [11], Chiu, Lirn [10], Huang, Tseng [4], Lu and } \\
\text { Yang [8] }\end{array}$ \\
\hline & IS2 & Inland transportations & Panova and Hilmola [6], Tseng, Huang [16] \\
\hline & IS3 & IT integral & Yang [9], Lu, Liao [3] \\
\hline & IS4 & Energy supply & $\begin{array}{l}\text { Chen, Wan [11], Chiu, Lirn [10], Huang, Tseng [4], Lu and } \\
\text { Yang [8] }\end{array}$ \\
\hline
\end{tabular}


30 agreed to join. Besides, to improve the survey's validity, an assistant was arranged to help each subject fill out questionnaires. After the two-month survey, 30 foreign manufacturers were successfully interviewed. Their profile is shown in Table 2.

Table 2 shows that surveyed respondents hold managerial positions, including presidential level (10\%), CEO/Vice-CEO (43.3\%), and Chief Officers (46,7\%). Besides, approximately $87 \%$ of respondents have at least ten years of work experience. Note that the respondents' high level of qualifications could give recognition to the reliability of survey results.

Since each participant is asked to assess perceived importance and satisfaction with ACs, 60 pairwise comparison matrices (PCMs), including 30 for importance level and 30 for satisfaction lev$\mathrm{el}$, are formed. For verifying the consistency of
60 PCMs, this study uses the Consistency Index (CI) and the Consistency Ratio (CR), as shown in Formulas 1 and 2:

$\mathrm{CI}=\frac{\lambda_{\max }-n}{n-1}$

and:

$\mathrm{CR}=\frac{\mathrm{CI}}{\mathrm{RI}}$

in which, $\lambda_{\max }$ denotes the principle eigenvalue for each matrix while $n$ represents the number of criteria in the matrix. Meanwhile, RI is a randomised index, as pointed out in Table 3 [2]. According to Saaty [13], $C R \leq 0.1$ demonstrates the consistency of the matrices.

This paper uses the software package Expert Choice 11.5 to find the PCMs' CI. Then, CR can be obtained by Equation 2. Results show that the CI of six samples or $\mathrm{CR}>0.1$, which means that they

Table 2 - The profile of respondents

\begin{tabular}{|c|c|c|c|}
\hline Characteristics & Range & Frequency & Percentage $(\%)$ \\
\hline \multirow{3}{*}{ Education } & Vocational college & 5 & 16.7 \\
\hline & University & 15 & 50.0 \\
\hline & Post-graduate & 10 & 33.3 \\
\hline \multirow{4}{*}{ Work experience } & $5-10$ & 4 & 13.3 \\
\hline & $11-15$ & 11 & 36.7 \\
\hline & $16-20$ & 9 & 30.0 \\
\hline & Above 21 & 6 & 20.0 \\
\hline \multirow{3}{*}{ Job title } & President/Vice-President & 3 & 10.0 \\
\hline & $\mathrm{CEO} /$ Vice-CEO & 13 & 43.3 \\
\hline & Chief Officers & 14 & 46.7 \\
\hline \multirow{2}{*}{ Type of FTZ } & Science park zone & 11 & 36.7 \\
\hline & Export processing zone & 19 & 63.3 \\
\hline \multirow{5}{*}{ Type of manufacturers } & Electronics & 9 & 30.0 \\
\hline & Plastics & 7 & 23.3 \\
\hline & Photoelectric sensors & 5 & 16.7 \\
\hline & Machinery & 3 & 10.0 \\
\hline & Chemicals & 6 & 20.0 \\
\hline \multirow{4}{*}{ Revenue (Billion US dollar) } & $10-20$ & 7 & 23.3 \\
\hline & $21-50$ & 9 & 30.0 \\
\hline & $51-100$ & 11 & 36.7 \\
\hline & Above 100 & 3 & 10.0 \\
\hline
\end{tabular}

Table 3 - Randomised index

\begin{tabular}{||c|c|c|c|c|c|c|c|c|c|c||}
\hline$n$ & 3 & 4 & 5 & 6 & 7 & 8 & 9 & 10 & 11 & 12 \\
\hline RI & 0.525 & 0.882 & 1.115 & 1.252 & 1.341 & 1.404 & 1.452 & 1.484 & 1.513 & 1.535 \\
\hline
\end{tabular}


are inconsistent [13]. Therefore, the questionnaires' subjects were asked to revise their ratings until the responses satisfied the consistency tests.

\subsection{The weights of $\mathrm{ACs}$}

By surveyed data, we can form 60 PCMs as mentioned above. For considering the linguistic fuzziness of respondents in answering surveys, a triangular fuzzy number parameterised by the measurement scores of minimum, geometric mean, and maximum is employed to aggregate the 60 matrices into two fuzzy positive reciprocal matrices (FPRM), one for importance measure and one for satisfaction measure. Based on these two matrices, a fuzzy AHP method is then adopted to weight the ACs, including measures of importance and satisfaction. For the convenience of explanation, we take the ACs' importance measures under the GE construct to explain the process of the fuzzy AHP method. The ACs under the GE construct, shown in Table 1, include four ACs: (GE1, GE2, GE3, GE4).

\section{The fuzzy positive reciprocal matrix}

Suppose $\widetilde{A}$ is a FPRM with $n$ ACs as:

$$
\widetilde{A}=\left[\widetilde{a}_{i j}\right]_{n \times n}=\left[\begin{array}{cccc}
1 & \tilde{a}_{12} & \cdots & \tilde{a}_{1 n} \\
\widetilde{a}_{21} & 1 & \cdots & \widetilde{a}_{2 n} \\
: & \vdots & & : \\
\widetilde{a}_{n 1} & \tilde{a}_{n 2} & \cdots & 1
\end{array}\right]
$$

in which, $\tilde{a}_{i j}$ is a triangular fuzzy number (TFN) characterised by parameters:

$$
\widetilde{a}_{i j}=\left\{\begin{array}{l}
{\left[l_{i j}, m_{i j}, u_{i j}\right], \text { if } i>j} \\
{[1,1,1], \text { if } i=j} \\
{\left[\frac{1}{u_{j i}}, \frac{1}{m_{j i}}, \frac{1}{l_{j i}}\right], \text { if } i<j}
\end{array}\right.
$$

If we have $t$ positive reciprocal matrix from $t$ respondents, then such $t$ matrices can be aggregated into a FPRM using Formula 4:

$$
\left[l_{i j}, m_{i j}, u_{i j}\right]=\left[\min _{1 \leq k \leq t}\left(a_{i j}^{(k)}\right),\left(\prod_{k=1}^{t} a_{i j}^{(k)}\right)^{1 / t}, \max _{1 \leq k \leq t}\left(a_{i j}^{(k)}\right)\right]
$$

where $i=1,2, \ldots, n, j=1,2, \ldots, n$ and $k=1,2, \ldots, t$.

For the ACs' importance measures under the GE construct, based on Equations 3 and 4, we have the GE construct's matrix $\widetilde{A}_{1}$ as:

$\widetilde{A}_{1}=\left[\begin{array}{l}{[1.000,1.000,1.000][0.250,1,220,6.000][0.333,3.514,9.000][0.333,1.714,8.000]} \\ {[0.167,0.819,4.000][1.000,1.000,1.000][0.250,2.587,9.000][0.167,1.078,9.000]} \\ {[0.111,0.285,3.000][0.111,0.387,4.000][1.000,1.000,1.000][0.167,0.387,4.000]} \\ {[0.125,0.583,3.000][0.111,0.927,6.000][0.250,2.587,8.000][1.000,1.000,1.000]}\end{array}\right)$

Further, by fuzzy operations, we can easily show that the $\widetilde{A}_{1}$ approximates a FPRM as Equation 3.

\section{The fuzzy AHP approach}

Theoretically, the AC's weights might be obtained from the eigenvector vector of $\bar{A}$. If $\widetilde{A}$ is a FPRM as Equation 3, Saaty [13] suggested four simplified methods to find the eigenvectors of $\widetilde{A}$, including NGMR (Normalisation of the Geometric Mean of the Rows), NRSC (Normalisation of the Reciprocal of Columns Sum), NRA (Normalisation of the Row Average) and ANC (Average of Normalised Columns). This article adopted the NGMR to calculate the ACs' weight in $\widetilde{A}$.

For the $i$ th $\mathrm{AC}(i=1,2, \ldots, n)$ in the matrix $\widetilde{A}$, its geometric means $\widetilde{g}_{i}$ may be computed as follows:

$$
\begin{aligned}
& \widetilde{g}_{i}=\left(\prod_{j=1}^{n} \widetilde{a}_{i j}\right)^{1 / n}=\left[\left(\prod_{j=1}^{n} l_{i j}\right)^{1 / n},\left(\prod_{j=1}^{n} m_{i j}\right)^{1 / n},\left(\prod_{j=1}^{n} u_{i j}\right)^{1 / n}\right], \\
& i=1,2, \ldots, n \\
& \Rightarrow \sum_{i=1}^{n} \widetilde{g}_{i}=\left[\sum_{i=1}^{n}\left(\prod_{j=1}^{n} l_{i j}\right)^{1 / n}, \sum_{i=1}^{n}\left(\prod_{j=1}^{n} m_{i j}\right)^{1 / n}, \sum_{i=1}^{n}\left(\prod_{j=1}^{n} u_{i j}\right)^{1 / n}\right]
\end{aligned}
$$

Based on Equations 5 and 6 , the weight $\widetilde{w}_{i}$ for the $i$ th $\mathrm{AC}(i=1,2, \ldots, n)$ can then be obtained as follows:

$$
\begin{aligned}
\widetilde{w}_{i} & =\frac{\widetilde{g}_{i}}{\sum_{i=1}^{n} \widetilde{g}_{i}} \\
& =\left[\frac{\left(\prod_{j=1}^{n} l_{i j}\right)^{1 / n}}{\sum_{i=1}^{n}\left(\prod_{j=1}^{n} u_{i j}\right)^{1 / n}}, \frac{\left(\prod_{j=1}^{n} m_{i j}\right)^{1 / n}}{\sum_{i=1}^{n}\left(\prod_{j=1}^{n} m_{i j}\right)^{1 / n}}, \frac{\left(\prod_{j=1}^{n} u_{i j}\right)^{1 / n}}{\sum_{i=1}^{n}\left(\prod_{j=1}^{n} l_{i j}\right)^{1 / n}}\right], \\
i & =1,2, \ldots, n
\end{aligned}
$$

Since the example $\widetilde{A}_{1}$ approximates a positive reciprocal matrix, the NGMR method can thus find its eigenvectors. Based on Equation 5, the geometric mean of $\widetilde{g}_{i}(i=1,2, \ldots, 4)$ can be found as:

$\left[\begin{array}{l}\widetilde{g}_{1} \\ \widetilde{g}_{2} \\ \vec{g}_{3} \\ \vec{g}_{4}\end{array}\right]=\left[\begin{array}{l}{[0.4082,1.6466,4.5590]} \\ {[0.2887,1.2295,4.2426]} \\ {[0.1982,0.4541,2.6321]} \\ {[0.2427,1.0876,3.4641]}\end{array}\right]$

By Equation 6, we have: $\sum_{i=1}^{4} \widetilde{g}_{i}=[1.1379,4.4179,14.897]$.

Finally, based on Equation 7, we can find the weight $\widetilde{w}_{i}$ for the $i$ th $\mathrm{AC}(i=1,2, \ldots, 4)$ as:

$\left[\begin{array}{l}\widetilde{w}_{1} \\ \widetilde{w}_{2} \\ \widetilde{w}_{3} \\ \widetilde{w}_{4}\end{array}\right]=\left[\begin{array}{l}{[0.0274,0.3727,4.0066]} \\ {[0.0194,0.2783,3.7286]} \\ {[0.0133,0.1028,2.3132]} \\ {[0.0163,0.2462,3.0444]}\end{array}\right]$

\section{Defuzziness}

As the weight $\widetilde{w}_{i}$ of the $i$ th $\mathrm{AC}(i=1,2, \ldots, n)$ in $\widetilde{A}$ is the fuzzy number, we deployed Buckley's index [4] to defuzzify the $\widetilde{w}_{i}$ into a crisp number $w_{i}(i=1,2, \ldots, n)$. For the convenience of explanations, let $\widetilde{w}_{i}=\left[l_{i}^{w}, m_{i}^{w}, u_{i}^{w}\right]$, where: 


$$
\begin{aligned}
& {\left[l_{i}^{w}, m_{i}^{w}, u_{i}^{w}\right]} \\
& =\left[\frac{\left(\prod_{j=1}^{n} l_{i j}\right)^{1 / n}}{\sum_{i=1}^{n}\left(\prod_{j=1}^{n} u_{i j}\right)^{1 / n}}, \frac{\left(\prod_{j=1}^{n} m_{i j}\right)^{1 / n}}{\sum_{i=1}^{n}\left(\prod_{j=1}^{n} m_{i j}\right)^{1 / n}}, \frac{\left(\prod_{j=1}^{n} u_{i j}\right)^{1 / n}}{\sum_{i=1}^{n}\left(\prod_{j=1}^{n} l_{i j}\right)^{1 / n}}\right] \\
& i=1,2, \ldots, n
\end{aligned}
$$

The Buckley's index (1981) of the $\widetilde{w}_{i}, i=1,2, \ldots, n$ is defined as follows:

$$
w_{i}=\left[l_{i}^{w} \cdot\left(m_{i}^{w}\right)^{2} \cdot u_{i}^{w}\right]^{\frac{1}{4}}, i=1,2, \ldots, n
$$

Normalising the $w_{i}(i=1,2, \ldots, n)$, the crisp weight $\omega_{i}$ of the $i$ th $\mathrm{AC}$ can then be obtained as follows:

$\omega_{i}=\frac{w_{i}}{\sum_{i=1}^{n} w_{i}}, i=1,2, \ldots, n$

For FPRM $\widetilde{A}_{1}$, based on Equations 8 and 9 , the $w_{i}$ and $\omega_{i}(i=1,2, \ldots, 4)$ for the ACs under the GE construct can be obtained as follows:

$w=[0.3514,0.2736,0.1343,0.2342$

$\Rightarrow \omega[0.3537,0.2754,0.2357]$.

Thus, we have the weights of (GE1, GE2, GE3, GE4) as $(35.37 \%, 27.54 \%, 13.52 \%, 23.57 \%)$.

\section{The FPRM's consistency}

In the manuscript, we tested the consistency for integrated fuzzy matrixes (also called FPRMs) using Wang and Lin (2017)'s definition [17], as follows:

Let $\widetilde{A}=\left(\widetilde{a}_{i j}\right)=\left(a_{i j}^{L}, a_{i j}^{M}, a_{i j}^{U}\right)_{n \times n}$ be the integrated fuzzy matrix, then its geometric consistency in$\operatorname{dex}(G C I)$ is defined as:

$$
\begin{aligned}
& \operatorname{GCI}(\widetilde{A})=\max \left\{\frac{2}{(n-1)(n-2)} \sum_{i<j}\left(\log a_{i j}^{M}-\frac{1}{n} \sum_{k=1}^{n} \log a_{i k}^{M}-\log a_{k j}^{M}\right)^{2}\right. \\
& \left.\frac{1}{(n-1)(n-2)} \sum_{i<j}\left[\log a_{i j}^{L}-\log a_{i j}^{U}-\frac{1}{n} \sum_{k=1}^{n}\left(\log a_{i k}^{L}+\log a_{i k}^{U}+\log a_{k j}^{L}+\log a_{k j}^{U}\right)\right]^{2}\right\}
\end{aligned}
$$

Besides, the GCI thresholds depend on the order of the comparison matrix, as shown below:

$$
G C I=\left\{\begin{array}{l}
0.3147 \text { if } n=3 \\
0.3562 \text { if } n=4 \\
0.3700 \text { if } n>5
\end{array}\right.
$$

Back to the GE construct's matrix $\widetilde{A}_{1}$, by virtue of Equation 10, its $G C I$ is computed as: $\operatorname{GCI}\left(\widetilde{A}_{1}\right)=$ $\max \{0.0277 ; 0.0082\}=0.0277$. Evidently, $G C I\left(\widetilde{A}_{1}\right)$ is less than its threshold of 0.3562 ; thus, the matrix $\widetilde{A}_{1}$ is consistent. In the same way, the results of the consistency test for the remaining integrated fuzzy matrixes are shown in Table 4.

\section{The global weights of ACs}

According to the above steps, local weights of all ACs in Table 5 can be found. Then, the ACs' global weight may be attained by multiplying the local weights of the ACs by their corresponding global weights. Table 5 shows the results of all global weights of the ACs for importance measures. Similarly, the global weights of the ACs of the satisfaction measures are shown in Table 6.

\subsection{The assessment model}

Based on the IPA (Importance-Performance Analysis) theory [18] and the AC weights in $T a$ bles 5 and 6, an assessment model for the FDI performance of FTPZs is proposed. First, the means for satisfaction and importance measures of both weights was $6.25 \%$. Based on these two means, the IPA matrix can be divided into four quadrants, as shown in Figure 2, by which each AC can then be assessed by its location in the quadrants. Figure 2 indicates three ACs (GE1, GE2, and PD3) located in Quadrant II. According to the IPA theory, those ACs are assessed as high importance and low

Table 4 - Results of the consistency test

\begin{tabular}{|c|c|c|c|c||}
\cline { 2 - 5 } \multicolumn{1}{c|}{} & Layer & GCI & Thresholds & Is it consistent? \\
\hline \hline \multirow{4}{*}{ Perceived importance } & Layer 1 & 0.3039 & 0.3562 & Yes \\
\cline { 2 - 5 } & Layer 2: PE & 0.0277 & 0.3562 & Yes \\
\cline { 2 - 5 } & Layer 2: PD & 0.1249 & 0.3562 & Yes \\
\cline { 2 - 5 } & Layer 2: CT & 0.2566 & 0.3562 & Yes \\
\cline { 2 - 5 } & Layer 2: IS & 0.1072 & 0.3562 & Yes \\
\hline \multirow{4}{*}{ Perceived satisfaction } & Layer 1 & 0.1428 & 0.3562 & Yes \\
\cline { 2 - 5 } & Layer 2: PE & 0.2747 & 0.3562 & Yes \\
\cline { 2 - 5 } & Layer 2: PD & 0.0305 & 0.3562 & Yes \\
\cline { 2 - 5 } & Layer 2: CT & 0.1630 & 0.3562 & Yes \\
\cline { 2 - 5 } & Layer 2: IS & 0.0958 & 0.3562 & \multicolumn{2}{|c||}{} \\
\hline
\end{tabular}


Hsu W-KK et al. An Evaluation Model for Foreign Direct Investment Performance of Free Trade Port Zones

Table 5 - Weights of investor's perceived importance on ACs

\begin{tabular}{|c|c|c|c|c|}
\hline $\begin{array}{l}\text { Layer 1: } \\
\text { Constructs }\end{array}$ & $\begin{array}{l}\text { Global weights in } \\
\text { Layer } 1(\%)\end{array}$ & $\begin{array}{l}\text { Layer 2: } \\
\text { ACs }\end{array}$ & $\begin{array}{c}\text { Local weights of ACs of } \\
\text { Layer } 2(\%)\end{array}$ & $\begin{array}{c}\text { Global weights of ACs } \\
\text { of Layer } 2(\%)\end{array}$ \\
\hline \multirow{4}{*}{$\begin{array}{l}\text { Government \& economy } \\
\text { (GE) }\end{array}$} & \multirow{4}{*}{31.45} & GE1 & 35.37 & 11.12 \\
\hline & & GE2 & 27.54 & 8.86 \\
\hline & & GE3 & 13.52 & 4.25 \\
\hline & & GE4 & 23.57 & 7.41 \\
\hline \multirow{4}{*}{$\begin{array}{l}\text { Production } \\
\text { (PD) }\end{array}$} & \multirow{4}{*}{22.73} & PD1 & 18.61 & 4.23 \\
\hline & & PD2 & 12.69 & 2.88 \\
\hline & & PD3 & 43.90 & 9.98 \\
\hline & & PD4 & 24.81 & 6.64 \\
\hline \multirow{4}{*}{$\begin{array}{l}\text { Cost } \\
(\mathrm{CT})\end{array}$} & \multirow{4}{*}{29.99} & CT1 & 23.26 & 6.98 \\
\hline & & CT2 & 23.95 & 7.18 \\
\hline & & CT3 & 27.87 & 8.36 \\
\hline & & CT4 & 24.92 & 7.47 \\
\hline \multirow{4}{*}{$\begin{array}{l}\text { Infrastructure } \\
\text { (IS) }\end{array}$} & \multirow{4}{*}{15.83} & IS1 & 28.42 & 4.50 \\
\hline & & IS2 & 23.93 & 4.79 \\
\hline & & IS3 & 16.67 & 2.69 \\
\hline & & IS4 & 30.68 & 4.86 \\
\hline
\end{tabular}

Table 6-Weights of investor's perceived satisfaction on ACs

\begin{tabular}{|c|c|c|c|c|}
\hline $\begin{array}{l}\text { Layer 1: } \\
\text { Constructs }\end{array}$ & $\begin{array}{l}\text { Global weights in } \\
\text { Layer } 1(\%)\end{array}$ & $\begin{array}{l}\text { Layer 2: } \\
\text { ACs }\end{array}$ & $\begin{array}{c}\text { Local weights of ACs of } \\
\text { Layer } 2(\%)\end{array}$ & $\begin{array}{c}\text { Global weights of ACs } \\
\text { of Layer } 2(\%)\end{array}$ \\
\hline \multirow{4}{*}{$\begin{array}{l}\text { Government \& economy } \\
\text { (GE) }\end{array}$} & \multirow{4}{*}{24.05} & GE1 & 21.45 & $\begin{array}{c}5.16 \\
\end{array}$ \\
\hline & & GE2 & 14.75 & 3.55 \\
\hline & & GE3 & 33.18 & 7.98 \\
\hline & & GE4 & 30.62 & 7.36 \\
\hline \multirow{4}{*}{$\begin{array}{l}\text { Production } \\
\quad(P D)\end{array}$} & \multirow{4}{*}{14.43} & PD1 & 24.22 & 3.49 \\
\hline & & PD2 & 21.39 & 3.09 \\
\hline & & PD3 & 33.24 & 4.80 \\
\hline & & PD4 & 21.15 & 3.05 \\
\hline \multirow{4}{*}{$\begin{array}{l}\text { Cost } \\
(\mathrm{CT})\end{array}$} & \multirow{4}{*}{35.51} & CT1 & 22.45 & 7.97 \\
\hline & & CT2 & 33.33 & 11.84 \\
\hline & & CT3 & 20.62 & 7.32 \\
\hline & & CT4 & 23.60 & 8.38 \\
\hline \multirow{4}{*}{$\begin{array}{l}\text { Infrastructure } \\
\text { (IS) }\end{array}$} & \multirow{4}{*}{26.01} & IS1 & 19.84 & 5.16 \\
\hline & & IS2 & 36.26 & 9.43 \\
\hline & & IS3 & 18.25 & 4.75 \\
\hline & & IS4 & 25.65 & 4.79 \\
\hline
\end{tabular}

satisfaction. Thus, the policies for those ACs should be "Concentrate here", indicating that the FTPZ authorities should pay more attention to improving those ACs. Likewise, the two ACs (IS2 and GE3) located in Quadrant IV are evaluated as low importance and high satisfaction. Policies for those ACs could be "Overkill". Therefore, resources for these ACs should be deployed elsewhere. Practically, the FTPZ authorities may consider transmitting part of these ACs' resources to the ACs in Quadrant II. As for the ACs in Quadrants I and III, the assessment results are good performances. According to the IPA theory, those ACs are identified as "Keep

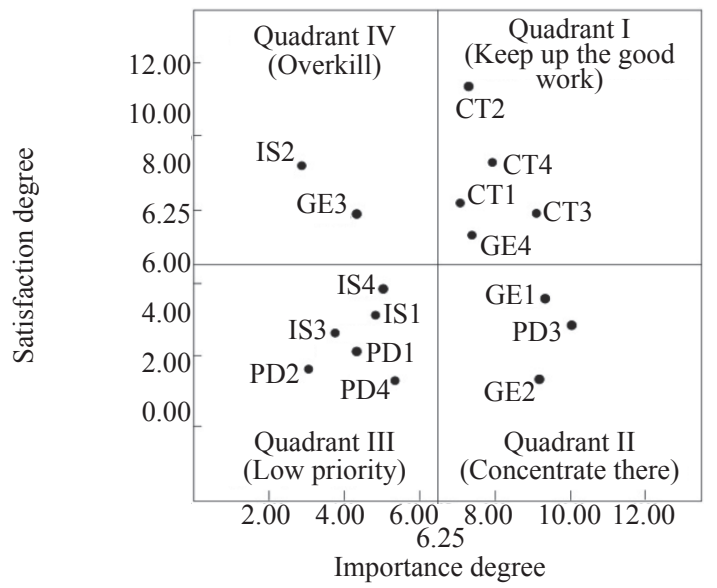

Figure 2 - Assessment results of the ACs 
up the good work" and "Low priority", respectively. Therefore, the policies for those ACs could just keep on operating, they do not need to change.

\section{DISCUSSION}

\subsection{The importance degree of ACs}

Table 5 shows that for the four constructs of ACs in the first layer, the investors are more concerned with Government \& economy (31.45\%) and Costs (29.99\%) for investments in FTPZs. Besides, for the ACs in Layer 2, the ACs with higher importance degree are PD3 (Raw material acquired, 9.98\%), GE1 (Political stability and social security, 9.91\%), GE2 (Local government efficiency, 8.93\%), and CT3 (Tax incentives, 8.36\%). This result could provide practical information for the FTPZ authority of the Kaohsiung port and the FTPZ managers of other countries to make improvement policies for their FTPZs' investment environments.

\subsection{The improvement priorities of ACs}

Concerning the ACs with higher improvement priorities in Quadrant I, we interviewed face-toface with some experts, including the FTPZ staffs of the Kaohsiung port and foreign manufacturers, by which some suggestions for FTPZ managers of the Kaohsiung port were suggested:

Improving GE1. To improve political stability and social security (GE1), FTPZ managers may ask the central government to adapt incumbent economic policies, especially fiscal and monetary policies. Like other countries in the world, political activities in Taiwan substantially impact economic policies, particularly the investment scheme. The investment attraction programs normally change considerably after the state election [3]. So, these political interventions typically lead to the instability of investment environments, and as a result, a reduction in FDI investors' confidence index.

Improving GE2. To enhance the efficiency of the local government administrations, FTPZ executives should set up a special division to contact the local government (i.e., the Kaohsiung municipalities). We know that most business activities of most enterprises in the FTPZ are directly controlled and managed by the FTPZ authorities and local governments. For FDI investors, FTPZ authorities and local governments are the administrative units responsible for censoring their applications. Therefore, the special division might enhance the managerial process for the local government.

Improving PD3. To advance the supply of raw materials (PD3), the open-door policy towards trade liberalisation should be implemented to encourage trade exchange between Taiwan and the rest of the world. In effect, Taiwan almost imports essential raw materials for production activities. For attracting FDI investors, this is a major drawback. Accordingly, a special policy to enable the import of raw materials is of paramount importance for the FTPZ of the Kaohsiung port. Such a policy is believed to appeal to more FDI investors. FTPZ managers could ask the Ministry of Economic Affairs to relieve restrictions on imported raw materials.

\subsection{Re-allocating scare resources}

As explained above, to leverage scarce resources effectively, FTPZ managers should re-allocate some resources from the ACs (IS2, GE3) in Quadrant IV (evaluated as "Overkill") to those ACs (GE1, GE2, PD3) in Quadrant II (assessed as "Concentrate here"). In practice, both human resources and budgets are the most imperative resources for departments of a company. Thus, the FTPZ managers of the Kaohsiung port may consider moving some of those resources from the departments working for the ACs (IS2, GE3) to ACs (GE1, GE2, PD3).

\section{CONCLUSION}

This paper aims to assess the FDI performance of FTPZs from the perspectives of foreign manufacturers. Firstly, based on the features of the FTPZs, 16 ACs are identified. A fuzzy AHP-based assessment model is then proposed to evaluate the FDI performance of FTPZs, by which FTPZ managers may make policies in improving their investment environments to attract more FDIs. The research model could provide managerial references for relevant research about FDI assessments.

To verify the proposed research model, foreign manufacturers around the FTPZ of the Kaohsiung port in Taiwan were empirically surveyed. Results point out that the criteria for investment environments in the FTPZ of the Kaohsiung port needing improvement are Acquirement of raw material, Political stability and social security, and Local government efficiency. Based on these results, some improvement policies were also suggested. Those 
results can provide valuable information for FTPZ managers of the Kaohsiung port to improve its investment environment. Further, since the Kaohsiung port is a famous merchant port globally, the results could also provide helpful information for other international ports.

This paper adopted the fuzzy AHP method to assess the ACs' weight for the FDI performance of FTPZs. It is worth noting that one of the basic assumptions is interdependences among all ACs when applying the fuzzy AHP. Yet, this research just asked several practical experts to verify interdependences during the survey design stage. Theoretically, this is maybe not rigorous enough. Further research may assess interrelations among the ACs and involve effects in the AHP approach.

Also, the FTPZ of the Kaohsiung port was empirically investigated to validate the assessment model. Pragmatically, different ports will be characterised by different investment environments. Accordingly, findings in this research cannot be absolutely suitable to other nations' FTPZs. Besides, this article conducted an empirical survey of 30 experienced foreign manufacturers in Taiwan to verify the model. This article uses a face-to-face interview instead of a mailed survey to improve the survey's validation. Therefore, the validity and reliability of the research results in this paper could be recognised. However, more representative samples might be needed in further research, especially in other areas, to confirm the empirical results.

\section{許文楷 教授. ${ }^{1}$}

电子邮件: khsu@nkust.edu.tw

黃秀慧 教授. ${ }^{2}$

电子邮件: hsheree@stu.edu.tw

阮黄新 博士生. ${ }^{1,3}$

电子邮件: i108189105@nkust.edu.tw;

huynhtannguyen@dntu.edu.vn

1 國立高雄科技大學 航運管理系

2 樹德科技大學 會展管理與貿易行銷碩士學位學程

3 越南同奈科技大学经济与管理学院.

\section{自由貿易港區之外商直接投資績效評估模式}

隨著國際化、全球化的發展, 多國簽署的區域經 濟協定已成為一種趨勢。在這樣的環境下, 一些具 有港口運輸功能的自由貿易港區 (FTPZ) , 成為外 商直接投資者 $(F D I)$ 最佳的投資地點選項之一。本文 主旨在評估 $F T P Z$ 之外商投資績效表現。本文首先 依據FTPZ的特性和相關文獻來建立外商投資績效的 評估準則 $(A C)$, 然後以模糊層級分析法 $(A H P)$ 為基 礎來建構評估模式, 並從外商投資者的觀點來評估 FTPZ 的績效表現。最後, 本文並以台灣高雄港的
FTPZ進行了實證研究。研究結果顯示, 目前高雄港 $F T P Z$ 最需要改進的 $A C$ 為: 原物料採購、地方政府的 效率、政治穩定和社會治安等, 針對此研究結果, 本文也對FTPZ 管理者提出了理論的管理意涵與和實 務上改善建議。

\section{關鍵詞：外商直接投資、績效、模糊層級分析} 法、自由貿易港區。

\section{REFERENCES}

[1] Bachmann C. Modeling the impacts of free trade agreements on domestic transportation gateways, corridors, and ports. Transportation Research Record. 2017;2611(1): 1-10. DOI: 10.3141/2611-01

[2] Hsu W-KK, Kao J-C. The safety of ship berthing operations at port dock-a gap assessment model based on fuzzy AHP. International Journal of Maritime Engineering. 2017;159: A377-A92. DOI: 10.3940/rina.ijme.2017. a4. 442

[3] Lu CS, Liao CH, Yang CC. Segmenting manufacturers' investment incentive preferences for international logistics zones. International Journal of Operations \& Production Management. 2008;28(2): 106-129. DOI: $10.1108 / 01443570810846865$

[4] Huang S-HS, Tseng W-J, Hsu W-KK. An assessment of knowledge gap in service quality for air freight carriers. Transport Policy. 2016;50: 87-94. DOI: 10.1016/j.tranpol.2016.06.006

[5] Chang CC, et al. Discussing the coordination barriers between divisions of free port zones in Taiwan. Maritimes Quarterly. 2014;23: 69-85. DOI: 10.1057/mel.2016.4

[6] Panova Y, Hilmola O-P. Justification and evaluation of dry port investments in Russia. Research in Transportation Economics. 2015;51: 61-70. DOI: 10.1016/j.retrec. 2015.07.008

[7] Deng X, Wang Y, Yeo G-T. Enterprise perspective-based evaluation of free trade port areas in China. Maritime Economics \& Logistics. 2017;19(3): 451-73. DOI: 10.1057/ mel.2016.4

[8] Lu C-S, Yang C-C. An evaluation of the investment environment in international logistics zones: A Taiwanese manufacturer's perspective. International Journal of Production Economics. 2007;107(1): 279-300. DOI: 10.1016/j.ijpe.2006.09.007

[9] Yang Y-C. A comparative analysis of free trade zone policies in Taiwan and Korea based on a port hinterland perspective. The Asian Journal of Shipping and Logistics. 2009;25(2): 273-303. DOI: 10.1016/S20925212(09)80006-0

[10] Chiu R-H, et al. An evaluation of free trade port zone in Taiwan. The Asian Journal of Shipping and Logistics. 2011;27(3): 423-45. DOI: 10.1016/S20925212(11)80020-9

[11] Chen J, et al. Evaluation and comparison of the development performances of typical free trade port zones in China. Transportation Research Part A: Policy and Practice. 2018;118: 506-26. DOI: 10.1016/j.tra.2018.09.009

[12] Hsu W-KK, Lian S-J, Huang S-HS. An assessment 
model based on a hybrid MCDM approach for the port choice of liner carriers. Research in Transportation Business \& Management. 2020;34: 100426. DOI: 10.1016/ j.rtbm.2019.100426

[13] Saaty RW. The analytic hierarchy process - what it is and how it is used. Mathematical Modelling. 1980;9(3-5): 161-76. DOI: 10.1016/0270-0255(87)90473-8

[14] Saaty TL. Fundamentals of decision making and priority theory with the analytic hierarchy process. Vol. 6. RWS Publications; 2000.

[15] Hsu W-K, Huang S-HS, Tseng W-J, Li D-F. An assessment of the policy gap in port selection of liner shipping companies. Transportation Letters. 2021;13(4): 273-81. DOI: $10.1080 / 19427867.2020 .1724648$
[16] Tseng W-J, Huang S-H, Zheng M-Z, Hsu W-K. Risk assessment of dangerous goods in airfreights. In: Lee T-CL, Wu C-HW, Lee PT-W. (eds.) International Forum on Shipping, Ports and Airports (IFSPA), 15-17 July 2015, Hong Kong Polytechnic University. Hong Kong: TRB Weekly; 2016. p. 1-19.

[17] Wang Z-J, Lin J. Acceptability measurement and priority weight elicitation of triangular fuzzy multiplicative preference relations based on geometric consistency and uncertainty indices. Information Sciences. 2017;402: 10523. DOI: 10.1016/j.ins.2017.03.028

[18] Martilla JA, James JC. Importance-performance analysis. Journal of Marketing. 1977;41(1): 77-9. DOI: $10.1177 / 002224297704100112$ 